\title{
A comparison of the eating quality of selected potato cultivars from two potato production regions in South Africa
}

\author{
Laryssa Booysen ${ }^{1}$, Annemarie T Viljoen ${ }^{1}$ and Hettie C Schönfeldt ${ }^{2}$ \\ Department Consumer Science, University of Pretoria, South Africa ${ }^{1}$, \\ Faculty of Natural and Agricultural Sciences, University of Pretoria, South Africa ${ }^{2}$
}

\begin{abstract}
BACKGROUND: Limited scientific information is available on the eating quality of potato cultivars in South Africa. This study aimed to determine, describe and compare the eating quality of three potato cultivars from two production regions (dry land and irrigated land) in South Africa, through sensory and physical evaluation. Sensory descriptors were identified for the sensory attributes and a lexicon was developed. A category scale was used to rate the sensory attributes and physical measurements of specific gravity, shear force resistance and scanning electron microscopy were performed.
\end{abstract}

RESULTS: It became evident that both sensory evaluation and physical measurements need to be performed in order to determine the eating quality of potato cultivars, as one evaluation supports the other. A Partial Least Squares regression modeling method was used to relate the sensory attributes and physical measurements. The intensity of the sensory attributes of the specific cultivars varied between the two production regions.

CONCLUSION: The eating quality of potatoes obtained from two production regions differed from another due to climatic conditions and other production characteristics that exist (dry-land versus irrigation). The study confirms the valuable contribution of determining the eating quality of potato cultivars.

Keywords: potato (Solanum tuberosum), eating quality, potato cultivars, potato production region, descriptive sensory evaluation, physical evaluation 


\section{INTRODUCTION}

South Africa is the fourth largest producer of potatoes in Africa, and continues to expand. During the 2005 to 2006 production year, South Africa, for example, produced approximately 1719 tons of potatoes and during the 2009 to 2010 production year 1947 tons, were recorded. ${ }^{1}$. Due to the large volumes consumed in this country, potatoes are regarded as a significant vegetable crop. Numerous cultivars are available and more are added continually. There are currently, approximately 40 registered cultivars in South Africa (http://www.potatoes.co.za). Cultivation conditions (e.g. soil, climate, precipitation and fertilisation) vary between countries and even between regions within a country. This contributes to differences in eating quality attributes observed amongst cultivars grown in different production regions.

Within the context of Southern Africa being a semi-arid region, different growing and climatic conditions exist in the various potato production regions of South Africa. The major potato producing regions in South Africa are the Eastern Free State, Western Free State, Limpopo, KwaZulu-Natal and Mpumalanga where production takes place throughout the year under different climatic conditions ${ }^{2}$ Potatoes are often considered a high water usage $\mathrm{crop}^{3}$ and are very susceptible to water deficit. Successful potato production thus depends on sufficient water supply during the crop's growing season. Two potato production methods, namely dry-land and irrigation are used to produce potato crops. During the past two decades there has been a prominent shift away from dry-land production towards production under irrigation in South Africa. Presently, approximately $80 \%$ of the crop is grown under irrigation or supplemented with irrigation (http://www.potatoes.co.za). ${ }^{4}$

Potatoes are characterised according to their growing period and end-use. Each potato cultivar is assumed to have specific characteristics with regard to size, shape, cooking and eating qualities in comparison to other cultivars from the same region. ${ }^{5}$ The assumption is that the eating quality of different potato cultivars grown in South Africa is unique and that the sensory attributes such as 
appearance, aroma, flavour, texture and after-taste differ from the eating quality of potatoes produced in other parts of the world.

The eating quality of potatoes is determined by both physical and sensory attributes which are determined by the potato's structure and chemical composition. Physical attributes are those related to the structure of the potato (dry matter and specific gravity) as well as the chemical composition of the potato (for example the starch composition). Therefore, texture as an expression of the structural, physical and mechanical properties of plant tissue is of utmost importance in consumers' perception of potato quality. ${ }^{6}$ Sensory evaluation relates directly to the textural attributes of a potato such as the first bite (hardness in the mouth, and firmness/compactness), while the physical measurement of specific gravity of potatoes relate to mastication which in turn impacts on the sensory evaluation of graininess, mealiness, moistness and dryness. The sensory attributes of potatoes determine the culinary application thereof and it varies between cultivars and production region. ${ }^{6,7}$ The unique sensory and physical attributes of potato cultivars are important in culinary preparations and should be described by a trained panel. ${ }^{7}$ The biological variation between potato tubers of the same cultivar is high, and it is known to influence the texture of cooked potatoes. ${ }^{8,9}$

As different growing and climatic conditions exist in different potato production regions in South Africa, the aim of this study was to determine, describe and compare, the eating quality of three selected potato cultivars from two production regions namely an irrigated (Limpopo province) and a dry-land (Eastern Free State) region. During 2006, the Limpopo region represented 16 $\%$ of the total hectares planted with potatoes in South Africa, and produced approximately $22 \%$ of the total harvest. The Eastern Free State region represented $18 \%$ of the total hectares planted, and produced approximately 12 $\%$ of the total summer harvest. ${ }^{4}$ 
Three potato cultivars, namely BP1, Mondial and FrutiLay were used in this study. BP1 is a South African cultivar with a white skin and flesh colour and has an oval slightly flattened shaped tuber. ${ }^{11}$ The Mondial cultivar has a pale yellow skin flesh colour and an oval to long tuber shape. Both these cultivars have a medium growing period of 90-110 days from emergence to natural foliage dieoff with a high yield potential with medium- to large-sized tubers under favourable growing conditions ${ }^{11}$ The FrutiLay cultivar represents a group of processing potato cultivars with a high dry matter (HDM) content and served as control.

\section{MATERIALS AND METHODS}

The study was conducted in two phases. Phase 1 involved descriptive sensory evaluation performed by a trained sensory panel, whereas phase 2 dealt with physical measurements to obtain objective data on the three cultivars.

\section{Sample and sampling method}

The potato samples were drawn from different farmers in each of the production regions. In each of the regions, three farmers (producers), using similar agricultural production methods (thus similar growing and harvesting conditions) were selected and potato samples from each farmer within the two regions were gathered. Potatoes (60 kg of each cultivar) were randomly sampled from different areas and put into brown paper bags. All the samples were at the same physiological age and were harvested on the same day during the first week of February 2007. All samples were transported the next day to the analytical facility at the Agricultural Research Council, Irene, Pretoria. Upon reception of the samples, they were removed from the brown paper bags and placed in crates in a dark, ventilated room at a moderate room temperature of $18{ }^{\circ} \mathrm{C}$. Each crate was marked with a randomly selected three- digit code to minimise bias. 
Six medium-sized potatoes from each cultivar were selected, weighing raw between 180 and $240 \mathrm{~g}$ each. Simple random sampling was used when selecting cultivar samples for cooking each day in preparation for the sensory evaluation. The potatoes were washed and scrubbed to remove any soil or dirt present.

\section{Preparation of samples for the sensory evaluation}

Potatoes of each cultivar from the two production regions were placed into twolitre stainless steel saucepans and boiled in their skins. Water at room temperature $\left(22{ }^{\circ} \mathrm{C}\right.$ was added to cover the potatoes. Each saucepan was covered with a lid (to prevent excessive moisture loss) during the cooking process. The boiling process started at room temperature and the heating rate was controlled at boiling temperature. Water was replenished, when required, to ensure that the potatoes were constantly covered with water. The boiling time varied slightly between the different cultivars but ranged between 50 and 75 minutes. The core temperature was measured with a hand-model KaneMane probe equipped with a T-type thermocouple. The potatoes were cooked until soft. An indicator of softness was when a core temperature of between 92 ${ }^{\circ} \mathrm{C}$ and $93^{\circ} \mathrm{C}$ was reached.

The potatoes were removed from the heat, drained and weighed to determine the change in moisture. The potatoes were transferred to a pre-heated glass bowl and kept warm at $75^{\circ} \mathrm{C}$ in calibrated Miele (H217) ovens for 10 minutes. After the resting period, the potatoes were cut into sample sizes (half of the potato) vertically from top to bottom. The mass range of each sample varied according to the size of the potato but was approximately $50 \mathrm{~g}$ each. Each sample was wrapped in aluminium foil and coded with a three-digit code. Samples were kept warm at $75^{\circ} \mathrm{C}$ in calibrated Miele (H217) ovens for 10 minutes before serving it to the panel within 3 to 5 minutes. Panel members were provided with water and carrot rings, which served as palate cleansers between evaluation sessions. ${ }^{9}$ During training carrots were indentified by the panel members as the most suitable palate cleansers for potatoes. Descriptive 
sensory evaluation was performed under red light conditions in the Agricultural Research Council's individual sensory evaluation booths that were controlled climatically at a room temperature of $22^{\circ} \mathrm{C}$.

Uniformity of each sample (volume served and serving temperature) was ensured and half of a potato in the skin was served to each panel member for evaluation. The samples were served at a controlled serving temperature of between $82{ }^{\circ} \mathrm{C}$ and $83^{\circ} \mathrm{C}$. The coded potato samples were served to the panel on pre-heated porcelain side plates on a white tray. Samples were randomised to exclude any bias due to the positioning effect.

\section{Descriptive sensory evaluation}

Panel members are recruited through advertising in the local media. Based on their availability and interest they are selected to be trained from a pool of about 100 individuals. After a week of training on basic flavour and aroma descriptors, they are again checked according to the repeatability and validity of their results. Subsequently approximately 10-20 panel members are then selected for participating on a particular product.

Ten trained experienced panel members performed the sensory evaluation. They were trained at the Agricultural Research Council, Irene in Pretoria to participate in this study. The training sessions took place over four consecutive days during which similar and different cultivars were evaluated to include new attributes and adapt to existing attributes with suitable descriptors. During training similar samples were served in a session to test repeatability of individual panel member's assessment.

Trained panel members received a sensory evaluation form describing the sensory attributes of aroma, texture, flavour and after-taste, to perform the descriptive sensory evaluation (Table 1). The lexicon of Thybo and Martens, ${ }^{12}$ 
was used as a point of reference and adapted to include the attribute descriptors of panel members.

Table 1. Lexicon used for the sensory attributes of potato cultivars (adopted from Thybo \& Martens, 1998) ${ }^{12}$

\section{AROMA}

Cooked potato

The aroma and flavour that refers to the internal portion of a baked or cooked potato as opposed to a raw potato

Potato/earthy

Aromatic notes associated with damp soil, wet foliage or slightly undercooked potatoes

Buttery

Aromatic notes associated with potato to which a small amount of butter has been added - a potato with more flavour, less bland

TEXTURE (Initial impression of appearance: visual or break with fork and evaluate the appearance of the texture)

Compression with the fork

Ease with which the potato is compressed with a small fork

Fracturability

Point of first fracture. Force with which the sample crumbles, cracks or shatters

First bite (Use half sample, in mouth, tongue on palate)

First bite: hardness in mouth

First chew:

Firmness/compactness

Graininess

Adhesiveness

Mealiness

Moistness

Dryness when swallowing

Cooked potato

Earthy/potato skin

Buttery

Blanched water/earthy
Force required to divide the potato in two parts by the front teeth

Degree of compression between molar teeth before item falls apart. Expresses the work (amount of mastication) before the potato is ready to be swallowed

\section{Mastication/chewing}

Expresses the content of grainy particles in the mouth after chewing Force required to remove potato sticking to teeth and palate after chewing

Expresses how mealy/crumbly the potato is experienced in the mouth after chewing

Expresses how moist the potato is experienced in the mouth and how much moisture that item releases in the mouth after chewing Evaluate the ease with which the sample is swallowed. Dryness in the throat

\section{FLAVOUR}

The flavour that refers to the internal portion of a baked or cooked potato as opposed to a raw potato Taste associated with earthy potato skin notes

A taste associated with potato to which a small amount of butter has been added - a potato with more flavour, less bland

A flavour of recycled water used to cooked potatoes, water is not fresh, slightly dirty, stale and earthy aroma

\section{AFTER-TASTE}

Metallic

A metallic-like taste that causes drying in the mouth 
An 8-point category rating scale was used to rate the intensity of each of the different sensory attributes of the different potato cultivars. ${ }^{13}$ One (1) on the category scale denoted the absence of the condition (e.g. no potato aroma) and eight (8) denoted the most intense condition (e.g. extremely intense potato aroma). Each sensory attribute (aroma, texture, flavour and after-taste) was measured. Four repetitions of each cultivar were applied during the sensory evaluation. The data on the sensory attributes for each session was captured in a Windows Excel spreadsheet.

\section{Phase two: Physical Evaluation}

In phase two physical measurement tests were conducted to collect objective data on the three potato cultivars. This included physical measurements of specific gravity, shear force resistance measurement and scanning electron microscopy (SEM).

Specific gravity is the ratio of the density of a food (or other substance) to that of water. ${ }^{14}$ Specific gravity was performed on raw potato tubers and calculated by the under-water-weight method by Es and Hartmans as described in Rastovski et al. ${ }^{15}$ The under-water-weight (UWW) refers to weight of a potato batch under water in grams as a calculation of the weight of the same potato batch above water. This formula of specific gravity was used to obtain the specific gravity of the potatoes, where

$$
\text { Specific Gravity (SG) }=\frac{\text { dry weight }}{\text { dry weight }- \text { (under-water-weight) }}
$$

Shear force resistance measurement refers to the force required to shear through a raw and/or a cooked potato. ${ }^{16}$ Cylindrical raw and cooked potato samples with a $12.5 \mathrm{~mm}$ core diameter were cored parallel to the length of the potato. The Warner Bratzler shear device mounted on a Universal Testing 
Machine (Instron 4500, Series IX, Version 5, Massachusetts) was used. A speed of $60 \mathrm{~mm} \cdot \mathrm{min}^{-1}$ with a $1 \mathrm{kN}$ load cell was applied. Eight cores per sample were tested. The reported value in $\mathrm{kg} / \mathrm{mm}$ represented the average of the peak force measurements of each sample.

Scanning Electron Microscopy (SEM) is a method to describe the surface structure of a solid by measuring the angle and energies of electrons scattered by the atoms (http://www.everyscience.com/Chemistry/Glossary/S.php). The image analysis is based on a resolution of the structure in the image, the socalled texture of the image. Image texture is viewed as a regular pattern that fills fragments of image surface. Scanning Electron Microscopy was performed on raw potato tubers. This method was done to illustrate the internal structure of the cultivars. The cubes were cut in the length with a sharp $3 \mathrm{~mm}$ blade into approximately $20 \mathrm{~mm}$ long $1 \mathrm{~mm}^{2}$ cubes and fixated in $2 \mathrm{ml}$ fixation medium. The fixation medium consisted of $2 \mathrm{ml} 2.5 \%$ formaldehyde, $2 \mathrm{ml} 2.5 \%$ Glyceraldehyde, $10 \mathrm{ml} \mathrm{Na} / \mathrm{K}$ buffer and $5 \mathrm{ml}$ distilled water. After 24 hours the samples were dried overnight in a Critical Point Dryer (Bio-Rad E3000, Watford, England), after which the samples were coated with gold by a Polaron E5200C Sputter Coater (Watford, England). Scanning Electron Microscopy was performed by a JSM-840 Scanning Electron Microscope (JEOL, Tokyo, Japan).

\section{Data analysis}

During data exploration, using GenStat ${ }^{1},{ }^{17}$ outliers were identified and panel performance was investigated as well. Outlying data was checked for accuracy. A one-way ANOVA test was applied with Fisher's protected t-test least significant difference at $5 \%$ level of significance among cultivar means, as the final dataset was acceptably normal and cultivar variances homogeneous. Within a region, selected sensory attributes showed significant differences as obtained with GenStat ${ }^{\circledR .17}$ Principal component analysis (PCA) were performed to graphically illustrate the correlations between the different sensory attributes in order to establish whether different production regions and growing 
conditions have an effect on the sensory attributes of the cultivars with a regionto-region evaluation among the cultivars.

Partial Least Squares (PLS) regression modelling ${ }^{18}$ was applied to the two production regions and the three potato cultivars, to determine whether there are regional and/or cultivar differences. In the biplot, the $Y=$ dependent variables were the sensory attributes of 17 mean values per cultivar, and the $X=$ independent variables were six mean objective measurement values per cultivar. The PLS regression was applied to relate the sensory attributes to the objective measurements ${ }^{19,20}$ and to identify the most important attributes differentiating between the potato cultivars as well as between the two regions. In the data sets in which one or more of the variables are special or of more interest relative to some others - one would be able to detect broader patterns of interrelationships among products and among sensory characteristics. ${ }^{13,21}$

\section{RESULTS AND DISCUSSION}

\section{Sensory evaluation}

Table 2 presents the mean values of the sensory evaluation of the three potato cultivars from the two regions, namely Limpopo (irrigated) and the Eastern Free State (dry land).

The ANOVA analysis detected significant differences for 16 of the 17 sensory attributes between cultivars from Limpopo (irrigation). Significant differences were established for only five (earthy aroma, buttery aroma, compression, hardness and compactness) of the 17 sensory attributes that were measured between the cultivars from the Eastern Free State region (dry-land). Although the three cultivars from Limpopo (irrigation) indicated to have significant differences related to aroma, texture, flavour and aftertaste, the same cultivars from the Eastern Free State (dry-land) did not significantly differ from one another with regard to texture when chewing, flavour or after-taste. 
Table 2: Mean values of the sensory attributes of the three potato cultivars from the Limpopo region (irrigated) and the Eastern Free State region (dry-land)

\begin{tabular}{|c|c|c|c|c|c|c|c|c|c|c|}
\hline \multirow[b]{2}{*}{ ATTRIBUTE } & \multicolumn{5}{|c|}{ Limpopo (irrigated) } & \multicolumn{5}{|c|}{ Eastern Free State (dry-land) } \\
\hline & p-value & se & $\begin{array}{l}\text { BP1 } \\
\text { cultivar }\end{array}$ & $\begin{array}{l}\text { Mondial } \\
\text { cultivar }\end{array}$ & $\begin{array}{l}\text { HDM } \\
\text { cultivar }\end{array}$ & $\begin{array}{c}p- \\
\text { value }\end{array}$ & se & $\begin{array}{l}\text { BP1 } \\
\text { cultivar }\end{array}$ & $\begin{array}{l}\text { Mondial } \\
\text { cultivar }\end{array}$ & $\begin{array}{l}\text { HDM } \\
\text { cultivar }\end{array}$ \\
\hline \multicolumn{11}{|l|}{ AROMA } \\
\hline Cooked potato & 0.020 & 0.814 & $4.79^{\mathrm{a}}$ & $4.72^{\mathrm{a}}$ & $4.38^{\mathrm{b}}$ & 0.401 & 0.966 & 4.14 & 4.28 & 4.43 \\
\hline Potato/earthy & $<0.001$ & 0.921 & $2.18^{\mathrm{b}}$ & $2.88^{\mathrm{a}}$ & $2.20^{\mathrm{b}}$ & 0.001 & 1.020 & $3.50^{\mathrm{a}}$ & $2.88^{\mathrm{b}}$ & $2.39^{c}$ \\
\hline Buttery & $<0.001$ & 0.988 & $2.53^{\mathrm{a}}$ & $1.80^{\mathrm{b}}$ & $2.65^{\mathrm{a}}$ & 0.005 & 0.659 & $1.34^{\mathrm{a}}$ & $1.73^{b}$ & $1.82^{\mathrm{a}}$ \\
\hline \multicolumn{11}{|l|}{ TEXTUE } \\
\hline Compression with the fork & $<0.001$ & 0.824 & $3.06^{\mathrm{b}}$ & $2.75^{\mathrm{c}}$ & $3.80^{\mathrm{a}}$ & 0.033 & 0.592 & $2.77^{\mathrm{a}}$ & $2.60^{\mathrm{ab}}$ & $2.41^{\mathrm{b}}$ \\
\hline Fracturability & $<0.001$ & 0.853 & $2.62^{b}$ & $2.14^{\mathrm{C}}$ & $3.28^{a}$ & 0.801 & 1.229 & 4.83 & 4.95 & 4.77 \\
\hline $\begin{array}{l}\text { Hardness in mouth (first } \\
\text { bite) }\end{array}$ & $<0.001$ & 0.747 & $2.92^{b}$ & $2.66^{\mathrm{c}}$ & $3.53^{\mathrm{a}}$ & 0.017 & 0.940 & $3.22^{\mathrm{ab}}$ & $2.83^{b}$ & $3.42^{\mathrm{a}}$ \\
\hline $\begin{array}{l}\text { Firmness/compactness } \\
\text { (mouth) }\end{array}$ & $<0.001$ & 0.824 & $3.06^{b}$ & $2.75^{\mathrm{c}}$ & $3.80^{\mathrm{a}}$ & 0.045 & 1.051 & $3.47^{\mathrm{ab}}$ & $3.05^{\mathrm{b}}$ & $3.61^{\mathrm{a}}$ \\
\hline Graininess & $<0.001$ & 0.899 & $2.71^{\mathrm{b}}$ & $2.18^{\mathrm{C}}$ & $2.53^{\mathrm{a}}$ & 0.365 & 0.930 & 2.61 & 2.78 & 2.91 \\
\hline Adhesiveness/waxiness & $<0.001$ & 0.815 & $2.55^{\mathrm{b}}$ & $3.05^{\mathrm{a}}$ & $2.93^{\mathrm{a}}$ & 0.319 & 0.909 & 2.58 & 2.33 & 2.3 \\
\hline Mealiness & 0.025 & 1.021 & $2.46^{\mathrm{b}}$ & $2.82^{a}$ & $2.68^{\mathrm{ab}}$ & 0.334 & 1.147 & 2.78 & 2.95 & 3.16 \\
\hline Moistness & $<0.001$ & 0.640 & $3.04^{\mathrm{a}}$ & $3.07^{\mathrm{a}}$ & $2.35^{\mathrm{b}}$ & 0.129 & 0.834 & 3.06 & 2.68 & 2.93 \\
\hline Dryness upon swallowing & $<0.001$ & 0.814 & $2.73^{\mathrm{C}}$ & $2.97^{b}$ & $3.70^{\mathrm{a}}$ & 0.828 & 1.059 & 3.39 & 3.53 & 3.41 \\
\hline \multicolumn{11}{|l|}{ FLAVOUR } \\
\hline Cooked potato & 0.308 & 0.863 & 4.64 & 4.59 & 4.40 & 0.813 & 0.849 & 4.28 & 4.40 & 4.32 \\
\hline Earthy/potato & $<0.001$ & 0.880 & $2.12^{b}$ & $2.72^{\mathrm{a}}$ & $2.10^{\mathrm{b}}$ & 0.157 & 0.95 & 2.97 & 2.55 & 2.75 \\
\hline Buttery & $<0.001$ & 0.886 & $2.38^{a}$ & $1.73^{\mathrm{b}}$ & $2.53^{\mathrm{a}}$ & 0.275 & 0.672 & 1.61 & 1.85 & 1.80 \\
\hline Blanched vegetable water & $<0.001$ & 0.808 & $1.90^{\mathrm{b}}$ & $2.34^{a}$ & $2.03^{b}$ & 0.751 & 1.006 & 2.56 & 2.53 & 2.68 \\
\hline \multicolumn{11}{|l|}{ AFTER-TASTE } \\
\hline Metallic & 0.011 & 0.791 & $1.68^{\mathrm{b}}$ & $1.99^{\mathrm{a}}$ & $1.84^{\mathrm{ab}}$ & 0.425 & 0.809 & 1.86 & 2.00 & 1.77 \\
\hline
\end{tabular}

${ }^{\mathrm{abc}}$ means in a row for each production region, with different superscripts differ significantly

1 = lowest score of attribute; 8 = highest score of attribute 
A comparison of the objective measurements, including specific gravity, shear force measurement, and percentage softening, was performed for the three cultivars from the two production regions. . The results are presented in Table 3.

Significant differences were found between the cultivars from each region for specific gravity with the HDM cultivars from both regions having significantly higher specific gravity than the Mondial and BP1 cultivars. Mondial cultivars from both regions has significantly higher shear force resistance when raw, compared to the other two cultivar. HDM cultivars had the lowest resistance to shear force when raw. Although no significant difference in sheer force when cooked and cooled was observed between the three cultivars from the Eastern Free State (dry-land), the HDM cultivar from Limpopo had a significantly higher resistance to shear force when cooked and cooled than the other two cultivars from this irrigated region (Limpopo). .

\section{Principal component analysis}

Figure 1 represents the principle component (PC) biplot of the positioning of the three cultivars from the two production regions, relative to their sensory attributes. PC 1 explains $60.1 \%$ of the variation in the data of the sensory attributes of the different potato cultivars while PC 2 explains $27.4 \%$ of the variation in the sensory data. In this biplot it is evident that the first PC contrasts the two regions. The three cultivars of the dry-land region (Eastern Free State), appear on the right-hand side while the three cultivars of the irrigated region (Limpopo) appear on the left-hand side. It is also clear that the cultivar differences from the Eastern Free State region (dry-land), are less apparent with all three cultivars from this region plotted relatively close together. The three cultivars from the Limpopo region (irrigated)are much further apart. This correlates with the ANOVA analyses (Table 2) which found less significant differences between the attributes of the three cultivars from the Eastern Free State (dry-land), than between the three cultivars from the Limpopo region (irrigation). 
Table 3. Physical measurements of the cultivars from the Limpopo region (irrigated) and the Eastern Free State region (dry-land)

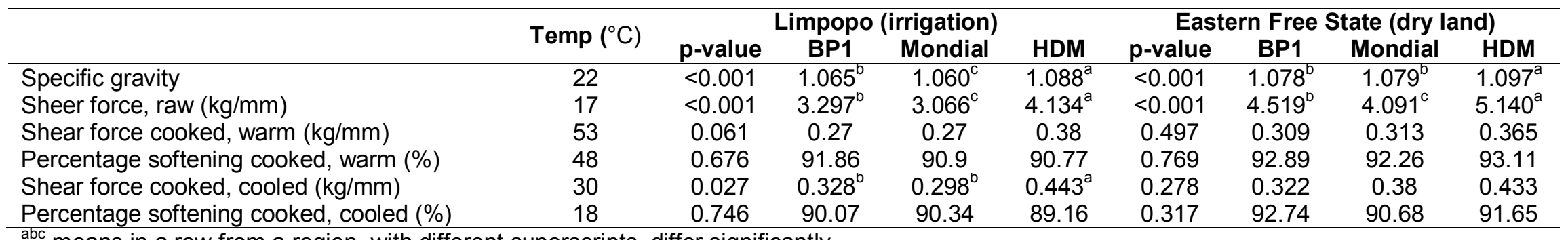

${ }^{\mathrm{abc}}$ means in a row from a region, with different superscripts, differ significantly 
The Mondial cultivar from the irrigated region (Limpopo) was characterised by having the sensory attributes of moistness, cooked potato flavour and aroma, and adhesiveness/waxiness whereas the BP1 and the HDM cultivars from this region were associated with a buttery aroma, compression with the fork and a buttery flavour as seen in Figure 1.

Figure 1. Principal component (PC) biplot of the positions of potato cultivars from both production regions relevant to their sensory attributes

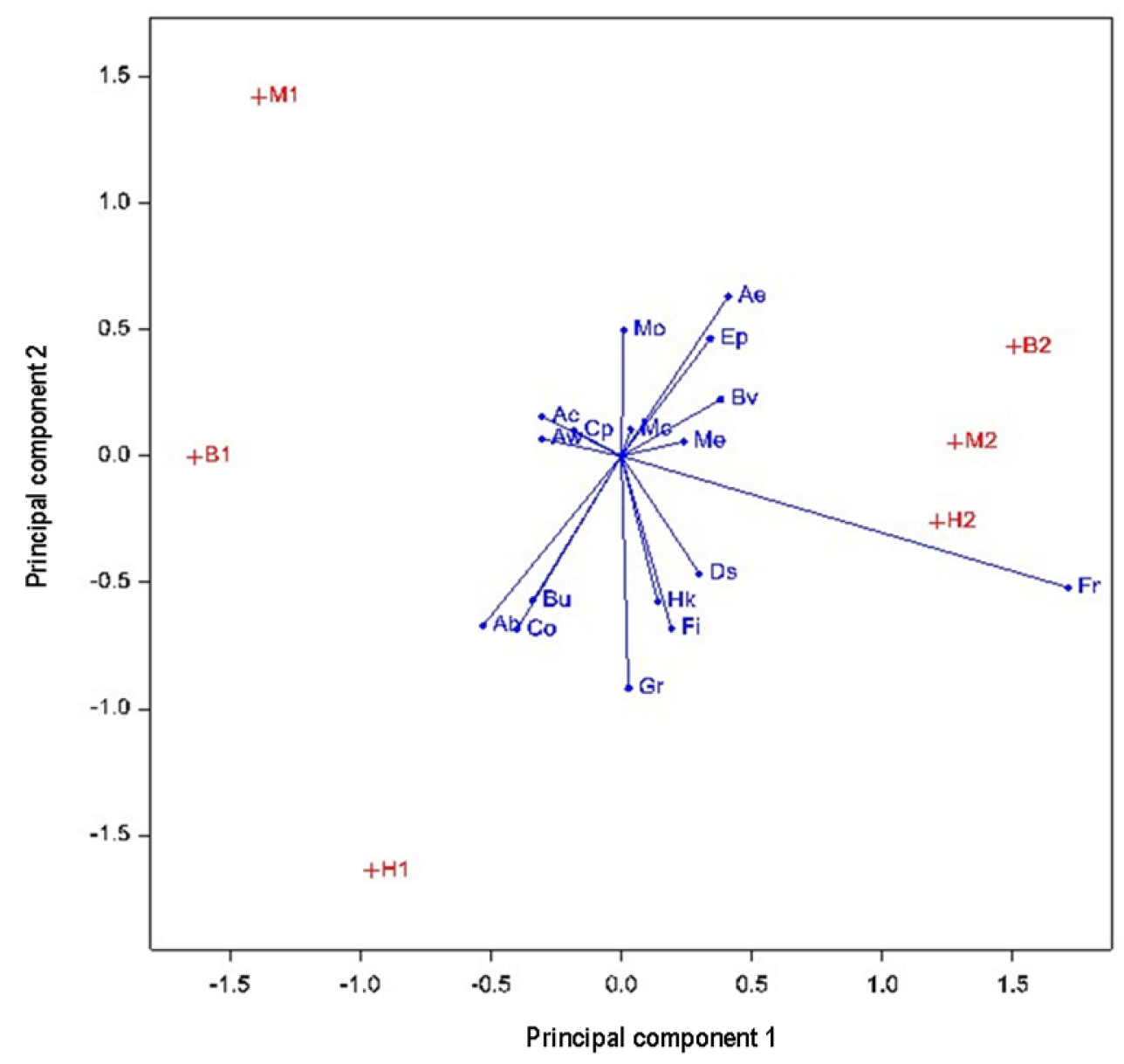

B1=BP1 cultivar from the Limpopo region; $M 1=$ Mondial cultivar from the Limpopo region; H1= HDM cultivar from the Limpopo region; B2= BP1 cultivar from the Eastern Free State region; M2= Mondial cultivar from the Eastern Free State region; H2= HDM cultivar from the Eastern Free State region; $A b=$ buttery arome; $\mathrm{Ac}=$ Cooked potato aroma; $\mathrm{Ae}=$ Earthy potato aroma; $\mathrm{Aw}=$ Adhesiveness $/$ waxiness; $\mathrm{Bu}=$ Buttery flavour; $\mathrm{Bv}=$ Blanced vegetable water flavour; $\mathrm{Co}=$ Compression with fork; $\mathrm{Cp}=$ Cooked potato flavour; Ds = Dryness upon swallowing; $\mathrm{Ep}=$ Earthy potato flavour; Fi = Firmness/compactness; Fr = Fracturability; $\mathrm{Gr}=$ Graininess; $\mathrm{Hk}=$ Hardness in mouth; $\mathrm{Mc}=$ Metallic aftertaste; $\mathrm{Me}=$ Mealines; Mo = Moistness 
In the dry-land region (Eastern Free State), the BP1 cultivar was characterised most by an earthy potato flavour and aroma, and a metallic after-taste, while a blanched vegetable water flavour, mealiness and fracturability were mostly associated with the Mondial cultivar. According to Van Marle et al., ${ }^{22}$ the uronic acid, arabinose and galactose are present in higher concentrations in the cooking medium of a mealy potato. The glucose found in the cooking medium is most likely originated from the starch and not from cellulose, which is not solubilised upon cooking. The HDM cultivar from the Eastern Free State was characterised by dryness upon swallowing, hardness with the first bite, firmness/compactness and graininess.

The differences in potato texture between the cultivars from different regions are due to the differences in structure and chemical composition. As stated by Abu-Ghannam and Crowley $^{23}$ the rigid structure of the raw potato is mainly due to the pectic substances, celluloses and hemicelluloses which develop as the tuber grows, and influences the objective characteristics of raw potatoes. Furthermore, according to Van Marle et al. ${ }^{24}$ the differences found between the pectic polysaccharides of the cultivars may influence the solubilisation of pectic polysaccharides during the cooking process. Part of the cell wall material solubilised during cooking originated from the middle lamellae. Textural differences between cooked potato cultivars are mainly due to the internal pressures that developed inside the cells resulting from the swelling of the gelled starch. ${ }^{25}$ Water absorption during cooking might lead to cell separation, reduced cohesiveness and softening. ${ }^{26}$

\section{Interpretation of the partial least squares (PLS) regression model on two production regions}

In the biplot (Figure 2), the $Y$ dependent variables were the sensory attributes per cultivar, and the $X$ independent variables were the six objective measurements. The PLS regression was applied to relate the sensory attributes to the objective measurements ${ }^{19,20}$ and to identify the most important 
Figure 2. Partial least square (PLS) regression model on two production regions

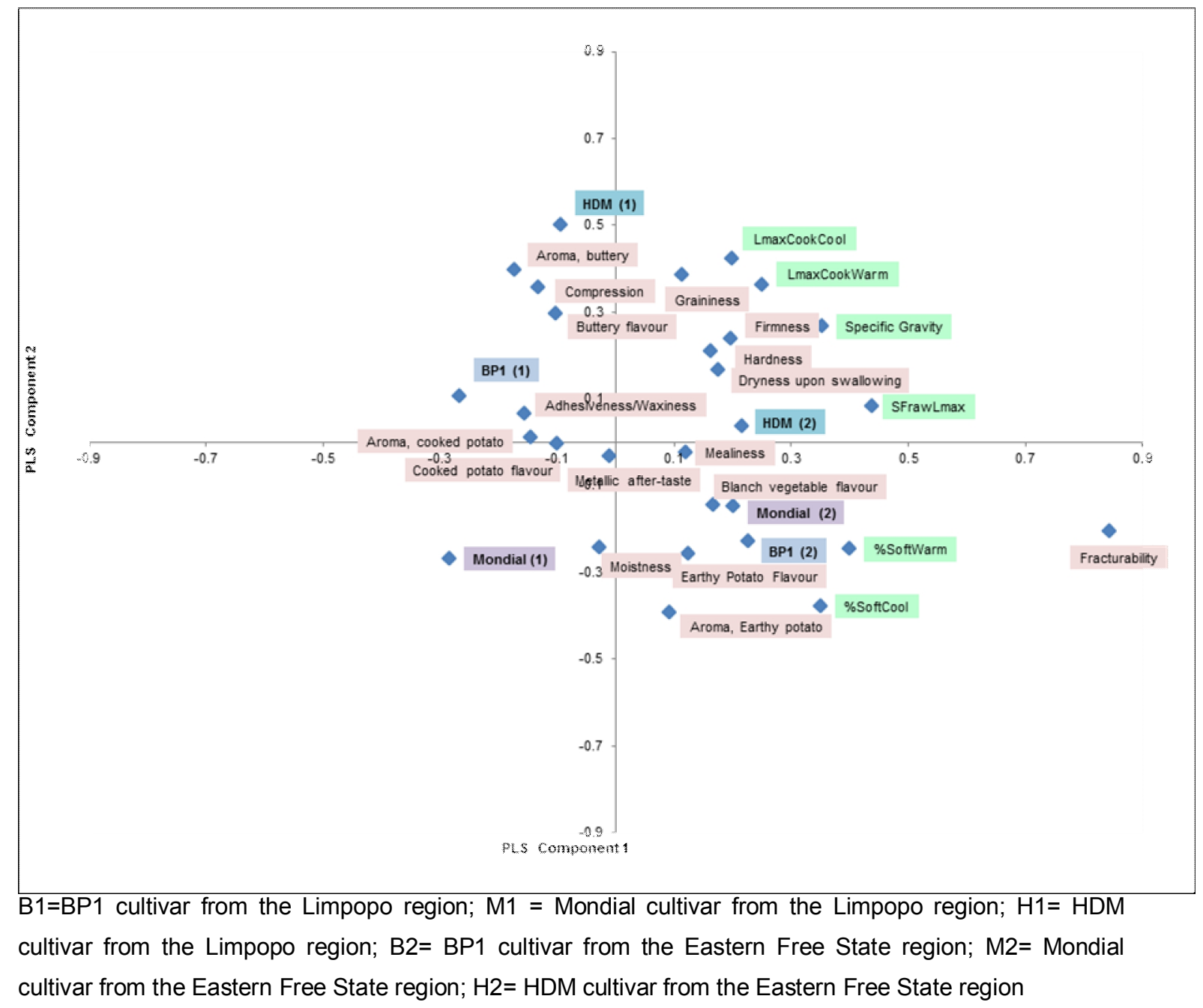

attributes differentiating between the three potato cultivars from the two regions. All the sensory attributes and objective test values used in the PLS regression model were taken as the means for each cultivar. ${ }^{27}$

The first dimension of the PLS regression model explains most of the variation in the data. A biplot of the $Y$ and $X$ matrix loadings indicates points for the 17 sensory attributes, the six objective measurements, and the three cultivars from two regions (Figure 2). In such plots, points close together are more similar and those farthest apart are dissimilar.

From the PLS biplot the three different cultivars (BP1, Mondial and HDM) from the Limpopo region (irrigation) contrast with the three cultivars from Eastern 
Free State region (dry-land) (Figure 2, PLS component 1 - vertical axis). The attributes explaining the variation the most across the vertical axis include fracturability, a cooked potato flavour and aroma, as well as the objective measurements of shear force raw, specific gravity and percentage softening cooked, warm (Figure 2). The cultivars grown in the Limpopo region were associated with high values of the physical measurements of shear force, raw, cooked, cooled and cooked, warm, specific gravity, percentage softening cooked, warm and cooled, and it can thus be said that they are more fractural than similar cultivars grown in the Eastern Free State region.

As different growing and climatic conditions exist in the two potato production regions, one cannot assume that identical cultivars will have similar intensities for their sensory and physical attributes. As depicted in Figure 2, similar cultivars (BP1, Mondial and the $\mathrm{HDM}$ ) in each of the production regions produced dissimilar results. The Limpopo region (irrigation) produced potatoes that were more cultivar-specific with associated sensory attributes of each cultivar. The dry-land growing conditions within the Eastern Free State region produce a slightly drier crop. Potatoes produced under these dry-land growing conditions were more fractural compared to potatoes produced under irrigated growing conditions. It is assumed that, due to the exposure of water stress situations, potato cultivars are very similar and drier in nature, while irrigated production produces different cultivars that are more distinctive and attributespecific in nature (Figure 1).

The HDM cultivars from both regions, but more dramatically in the HDM cultivar from the Limpopo region, contrasted the Mondial cultivars from both regions across the horizontal axis (Figure 2, PLS Component 2). The HDM cultivars indicated to be more grainy, buttery (aroma and flavour) and hard (higher resistance to shear force, cooled, cooked) than the Mondial cultivars from both regions.

Furthermore, the biplot indicates clearly that cultivar differences are less 
apparent (production points cultivars closer together) in the Eastern Free State, than in the Limpopo region which suggests that cultivar differences in a dry-land region are less evident compared to cultivar differences between potatoes produced in under irrigated conditions.

\section{CONCLUSIONS}

The intensity of the sensory attributes of the three cultivars evaluated varied between the two production regions. From the results obtained it is clear that the eating quality of the potatoes from the two production regions differed from one another due to climatic conditions and other production characteristics that exist (i.e. dry-land versus irrigation). The study confirms the need to determine and describe the eating quality of potato cultivars from all production regions in South Africa as significant differences occurred between the potatoes produced in these two regions.

\section{ACKNOWLEDGEMENTS}

The authors wish to acknowledge Potato South Africa for financial support to this study; the Agricultural Research Council, Irene, Pretoria for training the panel members and making their sensory evaluation facilities available; Ms Nicolette Gibson Hall who performed the physical evaluations and Ms Marie Smith for the statistical analysis. The contribution of the panel members who participated is greatly appreciated and acknowledged.

\section{REFERENCES}

1 Department of Agriculture, Forestry and Fisheries. Abstract of Agriculture Statistics (2011).

2 Potatoes South Africa. Potato Industry Statistics. Unpublished Report. Potatoes South Africa. Pretoria (2005).

3 Shock CC, Pereira AB and Eldredge EP, Irrigation best management practices for potato. Am J Potato Res 84:29-37 (2007). 
4 Chips, Official Magazine of Potato South Africa. 22(5):1-4 (2008).

5 Redmond GA, Gormley TR and Butler F, The effect of short- and longterm freeze-chilling on the quality of mashed potato. Innov Food Sci Emerg 4:85-97 (2003).

6 Seefeldt HF,Tønning E, and Thybo, AK, Exploratory sensory profiling of three culinary preparations of potatoes (Solanum tuberosum L.). J Sci Food Agric 91:104-112 (2011).

7 Seefeldt HF,Tønning E, Wiking $L$ and Thybo AK, Appropriateness of culinary preparations of potato (Solanum tuberosum L.) varieties and relation to sensory and physicochemical properties. J Sci Food Agric 91:412-420 (2011).

8 Thybo AK, Szczypinski PM, Karlson AH, Donstrup S, StodkildeJorgenson HS and Andersen HJ, Prediction of sensory texture quality attributes of cooked potatoes by NMR-imaging (MRI) of raw potatoes in combination with different image analysis methods. J Food Eng 61:91100 (2004).

9 Ross HA, McDougall GJ, Vincent JFV, Stewart D, Verall S and Taylor MA, Discerning intra-tuber differences in textural properties in cooked Solanum tuberosum group Tuberosum and group Phureja tubers. J Sci Food Agric 90:1527-1532 (2010).

10 Hills U and Pieterse L, World Catalogue of Potato Varieties, Agrimedia Germany (2005).

11 Visser AF Selecting a suitable potato cultivar. In Guide to potato production in South Africa, ed. by Niederwieser JG. ARC-Roodeplaat Vegetable and Ornamental Plant Institute, Pretoria (2003).

12 Thybo AK, and Martens M, Development of a sensory texture profile of cooked potatoes by multivariate data analysis. Journal of Texture Studies 29:453-468 (1998).

13 Lawless HT and Heymann H, Sensory Evaluation of food. Principles and Practices. Chapman \& Hall (1998).

14 McWilliams M, Foods. Experimental Perspectives. 4th ed. Prentice Hall (2001). 
15 Rastovski A, Van Es A, Hartmans KJ, Buitelaar N, De Haan PH, Maijers CP, Van der Schild JHW, Sijbring PH, Sparenberg H and Van Zwol, DBH. Storage of potatoes: Post-harvest behavior, storage practice, and handling. Wageningen. Netherlands (1981).

16 Chiavaro E, Barbanti D and Vittadini RM, The effect of different cooking methods on the instrumental quality of potatoes. J Food Eng 77:169_ 178 (2005).

17 Payne RW, Murray DA, Harding SA, Baird DB and Soutar DM, GenStat for Windows ${ }^{\circledR} 10^{\text {th }}$ ed. Introduction. VSN International, Hemel Hempstead, United Kingdom (2007).

18 Vargas M, Crossa J, Sayre K, Reynolds M, Ramirez ME and Talbot M, Interpreting genotype $\mathrm{x}$ environment interaction in wheat by partial least squares regression. J Crop Sci 38:679-689 (1998).

19 Peppard TL, Ramus SA, Witt CA and Siebert KJ, Correlation of sensory and instrumental data in elucidating the effect of varietal differences on hop flavour in beer. J ASBC 47:18-26 (1989).

20 Toscas, PJ, Shaw, FD, Beilken, SL. Partial least squares (PLS) regression for the analysis of instrument measurements and sensory meat quality data. Meat Sci 52:173-178.

21 Meilgaard M, Civille GV and Carr BT, Sensory evaluation techniques. $2^{\text {nd }}$ ed. CRC Press. New York (1991).

22 Van Marle JT, Stolle-Smits T, Donkers J, Van Dijk C, Voragen AGJ and Recourt K, Chemical and Microscopic characterisation of potato (Solanum tuberosum L.) cell walls during cooking. J Agric Food Chem 45:50-58 (1997a).

23 Abu-Ghannam $\mathrm{N}$ and Crowley $\mathrm{H}$, The effect of low temperature blanching on the texture of whole processed new potatoes. J Food Eng 74:335-344 (2006).

24 Van Marle JT, Recourt K, Van Dijk C, Schols HA and Voragen AGJ, Structural features of cell walls from Potato (Solanum tuberosum L.). Cultivars Irene \& Nicola. J Agric Food Chem 45:1685-1693 (1997b). 
25 Kaur L, Singh N, Sodhi NS and Gujral HS, Some properties of potatoes and their starches. Nr I. Cooking, textural and rheological properties of potatoes. J Food Chem 79:177-181 (2002).

26 Nourian F, Ramaswamy HS and Kushalappa AC, Kinetic changes in cooking quality of potatoes stored at different temperatures. J Food Eng 60:257-266 (2003).

27 Smith MF, Leighton CL, Morey L and Schönfeldt HC, Application of Partial Least Squares regression to relate tastiness of boiled potatoes to chemical and physical tests. S Afr J Plant Soil 26(1):31-35 (2009). 